\title{
Sinkretisme dalam Adat Tradisi Masyarakat Islam ${ }^{1}$
}

\author{
Ros Aiza Mohd Mokhtar \\ Universiti Malaysia Sabah, rosaiza@ums.edu.my \\ Che Zarrina Sa'ari \\ Universiti Malaya, zarrina@um.edu.my
}

\begin{abstract}
Abstrak
Dalam kajian agama, sinkretisme telah menjadi salah satu kategori konsep yang dibahaskan dan kontroversi disebabkan terma ini memberi gambaran "tidak suci" atau "tidak tulen". Walaupun terminologi sinkretisme telah lahir dan berkembang di Barat, namun ia telah turut digunakan oleh beberapa sarjana dalam menerangkan fenomena beragama dan pengamalan adat tradisi masyarakat Islam di Nusantara yang membawa kepada natijah penolakan adat tradisi oleh golongan reformis Islam. Oleh itu, makalah ini bertujuan menghuraikan konsep sinkretisme serta analisis Islam mengenainya bagi menjelaskan sinkretisme yang berlaku khususnya dalam konteks adat tradisi masyarakat Islam serta cadangan menanggapinya. Kajian ini merupakan kajian kualitatif iaitu data kepustakaan yang diperolehi dianalisis secara deskriptif dan analitikal bagi menjelaskan sinkretisme dalam adat tradisi masyarakat Islam. Kajian mendapati imej "tidak suci" atau "tidak tulen" yang dibawa oleh sinkretisme dalam adat tradisi masyarakat Islam boleh dikaitkan dengan percampuran elemen Islam dan pra Islam yang masih bercanggah dengan prinsip Tauhid. Ia adalah bersifat sementara dan boleh dikikis, manakala adat tradisi pula boleh diteruskan sekiranya tidak lagi wujud percanggahan tersebut.
\end{abstract}

Kata kunci: sinkretisme, pemikiran Islam, prinsip Tauhid, adat tradisi, masyarakat Islam

\section{Syncretism within the Traditional Culture of Muslim Community}

\begin{abstract}
In the study of religion, syncretism has conveyed a controversial concept and become one of the issues being debated because it depicted "impurity" or "not authentic". The term definitely has been widely used by Western scholars to elaborate the phenomenon of syncretism among ancient and Christian societies, but, at the same time it is also used in the context of the Muslim community, particularly in describing the practice of traditional culture in Malaysia and elsewhere that led to the rejection
\end{abstract}

1 Kajian ini dibiayai oleh Universiti Malaya di bawah geran IPPP, PG0282012B. 
of traditional culture by the Muslim reformers. Therefore, this paper aims to describe the concept of syncretism as well as to analyze this concept from Islamic perspective in order to explain how it appeared in the context of traditional culture and how we could perceive or deal with it. In this study, library research is used for the purpose of collecting data. The data were then analyzed in descriptive and analytical way in order to explain the syncretism within traditional culture of the Muslim society. The study found that the image of "impurity" or "not authentic" brought about by syncretism within the traditional culture of Muslim society related to the mixing of Islam and pre-Islamic elements which are still in conflict with the principle of Tawhid. It is temporary and can be extinguished, while the traditional culture may be continued if the conflict no longer exists.

Keywords: syncretism, Islamic thought, Tawhid, traditional culture, Muslims

\section{Pendahuluan}

Perkembangan terkini menyaksikan terminologi sinkretisme turut diguna pakai bagi membincangkan fenomena percampuran pelbagai identiti dalam agama dan budaya masyarakat Islam di Nusantara secara deskriptif dengan menjelaskan apa yang bercampur dan mengapakah ia terjadi. Hal ini secara tidak langsung menjurus kepada penerimaan dan penggunaan modelmodel sinkretisme sedia ada oleh sarjana Barat. Menyedari akan ketidaksesuaian model sinkretisme Barat dalam menjelaskan fenomena sinkretisme dalam masyarakat Islam, makalah ini cuba membahaskan sinkretisme dalam adat tradisi masyarakat menurut perspektif Islam.

\section{Konsep dan Model Sinkretisme Dari Perspektif Barat}

Istilah syncretismos pertama kali digunakan dalam era falsafah Greek kuno oleh ahli sejarah Greek, Plutarch (sekitar 46 atau 47 Masihi hingga 120 Masihi) untuk menggambarkan "bagaimana bangsa Cretan bertindak" iaitu menghentikan permusuhan sesama mereka dan bersatu untuk menghadapi musuh yang sama. ${ }^{2}$ Senario ini menggambarkan bahawa biarpun manusia berselisih faham

2 Rosalind Shaw \& Charles Stewart, "Introduction: Problematizing Syncretism," dalam Syncretism/ Anti-Syncretism: The Politics of Religious Synthesis, ed. Charles Stewart \& Rosalind Shaw (London \& New York: Routledge, 1994), 3. 
sesama saudara atau sahabat, namun mereka lebih suka bekerjasama antara satu sama lain dalam menghadapi bahaya yang sama daripada menjalin hubungan baik dengan musuh, yang mana ia telah menjadi prinsip dan amalan kebiasaan di Cretan. ${ }^{3}$ Sinkretisme versi Plutarch telah dikritik kerana tidak mempunyai apa-apa kaitan dengan sinkretisme agama dalam rujukan moden. Sebaliknya, versi moden sinkretisme merujuk kepada neoetimologism iaitu berasal dari synkerannumi yang bermaksud "campuran" perkara-perkara yang tidak sepadan. Bentuk ini telah digunakan bagi menggambarkan usaha penyatuan agama oleh ahli-ahli teologi Protestant dalam abad ke-16 dan ke-17 yang membawa maksud untuk menggabungkan, atau untuk mendamaikan perbezaan doktrin daripada mazhab yang berbeza dalam agama Kristian. ${ }^{4}$

Menurut Reese sinkretisme atau dalam bahasa Inggerisnya syncretism berasal daripada perkataan Greek synkretizein yang bermaksud menggabungkan. ${ }^{5}$ Ia merujuk kepada percampuran atau amalgamasi falsafah pemikiran, agama dan budaya yang berbeza. Siv Ellen Kraft memperincikan definisi sinkretisme sebagai mencampurkan idea dan praktik agama, dengan maksud sama ada salah satu mengambil sedikit atau banyak prinsip atau keduanya bersatu (amalgamasi) secara kosmopolitan dan sedikit bentuk politeistik. Sejajar dengan penggunaan ini, sinkretisme telah direkod dalam pekeliling gereja sebagai kekeliruan dan kekusutan dalam agama. ${ }^{6}$

Sementara itu, Robert Baird pula menyarankan sinkretisme sebagai konsep yang perlu diharamkan daripada kajian sejarah agama. Baird mengatakan bahawa proses percampuran adalah aspek yang biasa dalam sejarah agama. Dengan itu, baginya untuk menjelaskan sesuatu sebagai sinkretistik adalah ibarat tidak

3 Anita Maria Leopold \& Jeppe Sinding Jensen, ed., Syncretism in Religion (New York: Routledge, 2004), 14.

4 Ibid.

5 William L. Reese, Dictionary of Philosophy and Religion (New Jersey: Humanities Press Inc., 1980), 564, entri "syncretism."

6 Siv Ellen Kraft, "To mix or not to mix: Syncretism/ anti-syncretism in the history of theosophy," Numen: International Review for the History of Religions 49, no. 2 (2002), 142. 
menjelaskan sesuatu. ${ }^{7}$ Bangkangan Baird menyebabkan perbincangan sarjana Barat mengenai sinkretisme menjadi lebih hangat. Dalam membahaskan penggunaan konsep sinkretisme, pada dasarnya telah berkembang dua aliran yang utama. Aliran pertama ialah mereka yang berusaha mengelakkan penilaian (deskriptif) manakala aliran kedua pula bertegas membentuk penilaian (normatif). Hal ini menambah kekeliruan dalam memahami konsep sinkretisme kerana kedua-dua aliran menggunakan perkataan yang sama bagi kajian mereka yang bertentangan. $^{8}$

Golongan daripada aliran pertama menggunakan definisi yang lebih inklusif dan mencadangkan sinkretisme sebagai proses semula jadi sebagaimana yang berlaku dalam tradisi-tradisi yang prihatin dalam mempertahankan keaslian mereka. Antara golongan aliran ini ialah Shaw dan Stewart (1994) yang membincangkan sinkretisme dengan panjang lebar tanpa menawarkan definisi melampaui umum pengertian percampuran agama. Dalam tulisan yang terkemudian, Steward menawarkan konsep yang lebih luas kepada sinkretisme iaitu:

"Sinkretisme menimbulkan persoalan sejarah mengenai asalusul, hubungan budaya dan pengaruh yang diterima. Ini adalah soalan-soalan yang lazimnya boleh dirumuskan bagi memahami agama serta fenomena budaya lain. Dengan itu, analisis antropologi merupakan kajian lanjutan secara profesional daripada mod popular pemikiran tersebut. Sekurang-kurangnya prinsip-prinsip asas sinkretisme terdiri daripada mod untuk menggambarkan agama, dan pada peringkat yang lebih baik, boleh digolongkan ke dalam teori agama." 9

Robert Baird, "Syncretism and the History of Religion" dalam Syncretism in Religion, ed. Anita Maria Leopold \& Jeppe Sinding Jensen (New York: Routledge, 2004), 51-52.

8 Edwin Zehner "Orthodox Hybridities: Anti-Syncretism and Localization in the Evangelical Christianity of Thailand," Anthropological Quarterly 78, no. 3 (2005), 585-617.

9 Charles Stewart, "Syncretism as a Dimension of Nationalist Discourse in Modern Greece," dalam Syncretism/ Anti-Syncretism: The Politics of Religious Synthesis, ed. Charles Stewart \& Rosalind Shaw (London \& New York: Routledge, 1994), 128. 
Manakala Michael Pye mendefinisikan sinkretisme sebagai kewujudan bersama elemen daripada pelbagai identiti yang bersifat sementara dari berbagai-bagai agama atau pelbagai konteks dalam sesebuah bentuk agama yang koheren. Dengan itu, Pye menjelaskan tentang wujudnya ketegangan antara elemen amalgamasi (kehidupan bersama pelbagai identiti) dan rujukan agama. $^{10}$ Pendiriannya sejajar Reese yang menerangkan sinkretisme sebagai kombinasi berlainan kepercayaan secara tidak kritikal. ${ }^{11}$

Jelas kelihatan di sini bahawa perbincangan golongan deskriptif terhadap sinkretisme terhenti setakat isu "percampuran elemen yang pelbagai dan bercanggah antara satu dengan lain" tanpa mengaitkannya dengan isu "tidak suci" atau "tidak tulen" sesuai dengan imej mereka yang mengelak perbincangan yang bersifat normatif iaitu menilai sama ada betul atau salah.

Manakala sarjana dari aliran kedua yang dilihat perihatin akan terma tersebut mempertikaikan ketulenan tradisi yang dicampur, mendefinisikan sinkretisme dalam skop yang eksklusif. Mereka membincangkan sinkretisme daripada perspektif Kristian yang menggunakan terma sinkretisme merujuk hanya kepada proses percampuran yang membawa bahaya kepada tradisi Kristian. Hal ini sejajar dengan usaha The Evangelical Dictionary of World Mission yang mempamerkan definisi tradisional sinkretisme yang bersifat negatif iaitu "the replacement or ditution of the essential truths of the gospel through the incorporation of non-Christian elemen" $" 12$ Dalam hal ini, Evangelical mengidentifikasikan sinkretisme sebagai "terlalu banyak perubahan", dalam masa yang sama memberi definisi negatif iaitu perubahan tersebut "mengancam teras agama" yang melibatkan ciri tuhan dan Jesus serta autoriti kitab Bible. ${ }^{13}$ Kreamer pula menggambarkan sinkretisme sebagai percampuran elemen agama

${ }^{10}$ Michael Pye, "Syncretisme and Ambiguity," Numen: International Review for the History of Religions 18, no. 2 (1971), 93.

11 William L. Reese, Dictionary of Philosophy and Religion, 564, entri "syncretism."

12 Edwin Zehner, "Orthodox Hybridities: Anti-Syncretism and Localization in the Evangelical Christianity of Thailand," 585-617.

13 Ibid. 
yang tidak sah. ${ }^{14}$ Sementara Schineller pula menyarankan penggunaan terminologi inculturation yang bermaksud sinkretisme yang telah disahkan oleh gereja. Ini turut memberi gambaran jelas bahawa setiap gereja bertanggungjawab membudayakan nilai Kristian dalam situasi tertentu. Dalam surat pekeliling keagamaan (encyclical) oleh John Paul II bertajuk "Mission of the Redeemer", seksyen 52-55, menjelaskan keperluan dan maksud inculturation dalam misi gereja. ${ }^{15}$ Namun dalam masa yang sama, beliau berhasrat membuang terminologi sinkretisme kerana konotasinya yang negatif. Saranan Schineller menimbulkan reaksi daripada Schreiter. Schreiter menekankan kepentingan terminologi sinkretisme untuk keperluan inculturation. ${ }^{16}$

Perbincangan golongan normatif terhadap sinkretisme nampaknya tidak terhenti setakat isu "percampuran elemen yang pelbagai dan bercanggah antara satu dengan lain" sebaliknya mengaitkannya dengan isu "tidak suci" atau "tidak tulen" yang membawa kepada pencemaran dan keterpesongan sesebuah agama khususnya agama Kristian. Walaupun ada isu untuk membuang terma sinkretisme yang berkonotasi negatif, namun penggunaannya dikekalkan bagi menggambarkan usaha awal missionari dalam menyebarkan Kristian ke dalam masyarakat bukan Kristian.

Dalam perbincangan deskriptif tentang sinkretisme, Colpe menyedari konsep sinkretisme tidak dapat diaplikasikan secara universal, lalu membahagikan sinkretisme kepada dua konsep serta mencadangkan tipologi atau model bagi menerangkan fenomena sinkretisme. Menurut beliau, konsep sinkretisme boleh dijelaskan sama ada sebagai 'perihal' (state) atau 'proses' (process). Konsep 'perihal' digunakan contohnya sebagai keseluruhan agama atau komponen tertentu dalam agama tersebut dijelaskan sebagai sinkretik. Manakala konsep 'proses' digunakan apabila wujud kecenderungan untuk bersifat sinkretik atau sebuah

14 Hendrik Kreamer, "Syncretism," dalam Syncretism in Religion, ed. Anita Maria Leopold \& Jeppe Sinding Jensen (New York: Routledge, 2004), 41.

15 Peter Schineller, "Inculturation and syncretism: what is the real issue?" International Bulletin of Missionary Research 16, no. 2 (1992), 50-53.

16 Robert J. Schreiter, "Defining Syncretism: An Interim Report", International Bulletin of Missionary Research 17, no. 2 (1993), 50-53. 
perkembangan yang berakhir dengan sinkretisme. ${ }^{17}$ Walau bagaimanapun menurut beliau lagi, dalam banyak contoh yang berkaitan dengan masyarakat Islam, pada dasarnya bentuk sinkretisme akan hilang disebabkan berlakunya pemisahan atau pemindahan elemen yang bercanggah dengan prinsip agama Islam tersebut. ${ }^{18}$

Bagi menjelaskan konsep sinkretisme berbentuk 'perihal', Colpe mencadangkan dua perkara pokok iaitu hubungan kesatuan yang kompleks dan menyeluruh (relations between complex whole) dan hubungan antara komponen tertentu (relations between particular components). ${ }^{19}$ Penyatuan yang kompleks atau menyeluruh boleh berlaku dalam aspek inter agama (between religions) dan intra agama (within religions). Contohnya penyatuan kompleks inter agama ialah sistem teologi yang terbentuk daripada Konfusianisme, Taoisme dan Buddhisme. Ketiga-tiga kepercayaan ini lengkap melengkapi antara satu sama lain. Manakala contoh penyatuan intra agama pula ialah agama di India iaitu dewa-dewa seperti Savitri, Indra, Vayu, Aryaman, Rudra, Agni Surya dan Yama dianggap sama di antara satu sama lain. ${ }^{20}$ Hubungan antara komponen tertentu pula boleh terjadi dengan dua cara yang utama iaitu penambahan (addition) dan pensejajaran (parallelization). Dalam konteks penambahan (addition), ia boleh terjadi dalam bentuk teokrasi (penggabungan tuhan-tuhan atau dewa-dewa) dan bentuk peribadatan. ${ }^{21}$ Dalam konteks pensejajaran (parallelization) pula, ia boleh terjadi dalam bentuk interpretasi, persamaan taraf (equivalence), dan identifikasi terhadap dewa-dewi. Interpretasi dianggap sebagai fasa utama sinkretisme. Persamaan taraf (equivalence) pula merupakan prasyarat dalam semua bentuk pensejajaran, identifikasi, teokrasi dan penyatuan sinkretisme yang kompleks. ${ }^{22}$

Konsep yang diperkenalkan oleh Colpe tersebut nampaknya sesuai sebagai rujukan asas tentang sinkretisme yang berlaku dalam masyarakat secara umum termasuklah proses sinkretisme

17 Carsten Colpe, "syncretism", dalam, The Encyclopedia of Religion, ed. Mircea Eliade (New York: McMillan Publishing, 1987), 14: 219-220.

18 Ibid, 226.

19 Ibid, 219.

20 Ibid, 222-223.

21 Ibid, 223-224.

22 Ibid, 224-225. 
yang berlaku dalam masyarakat Islam yang lazimnya berakhir dengan hilangnya sinkretisme. Manakala, model yang diperkenalkan oleh Colpe lebih mencakup sistem teologi yang melibatkan percampuran doktrin agama atau penyatuan dewadewi. Model ini nampaknya hanya sesuai dalam rangka menerangkan fenomena sinkretisme dalam konteks agama atau kepercayaan yang bersifat politeistik.

Berdasarkan pandangan sarjana Barat yang dibincangkan, dapatlah dirumuskan bahawa elemen utama dalam perbincangan sinkretisme ialah "percampuran pelbagai identiti yang tidak sepadan" dalam agama. Percampuran yang tidak sepadan tersebut dikaitkan dengan kemasukan benda asing yang bercanggah dengan prinsip agama ke dalam entiti agama tersebut. Ia membawa imej "tidak suci" atau "tidak tulen" kerana sesebuah agama lazimnya dikaitkan dengan suci dan tulen. Walau bagaimanapun, sarjana Barat beraliran deskriptif menghentikan perbincangan mereka tentang sinkretisme setakat "percampuran pelbagai identiti yang tidak sepadan" dalam agama tanpa menilai sama ada ia membawa imej "tidak suci" atau "tidak tulen". Definisi "percampuran pelbagai identiti yang tidak sepadan" yang menyebabkan pencemaran terhadap sesebuah agama tersebut boleh diperbahaskan dari perspektif Islam dengan lebih lanjut iaitu berkenaan konteks bagaimanakah dalam adat tradisi yang dianggap sebagai tidak sepadan sehingga membawa kepada pencemaran agama Islam tersebut.

\section{Sinkretisme dari Perspektif Al-Quran dan Sarjana Islam}

Dalam menjelaskan ketidakharusan sinkretisme dalam urusan agama dan peribadatan, Hamka ${ }^{23}$ dan Abu Jamin Roham ${ }^{24}$ sependapat mengatakan bahawa surah al-Kāfirūn ayat 1 hingga 6 sebagaimana berikut diturunkan sebagai menjawab persoalan sinkretisme:

${ }^{23}$ Lihat, Hamka, Tafsir al-Azhar (Singapura: Pustaka Nasional Pte Ltd, 2003), 10: $8132-8134$.

24 Lihat, Abu Jamin Roham, "sinkretisme" dalam Ensiklopedia Lintas Agama (Jakarta: Emerald, 2009), 642-643. 


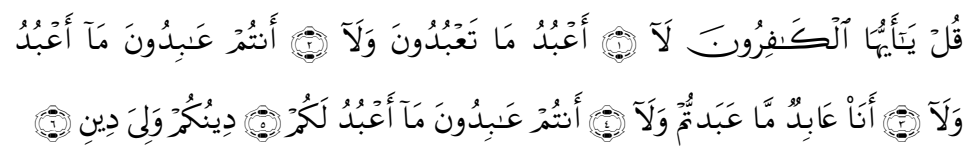

Al-Kāfirūn 109: 1-6

Maksudnya: Katakanlah (Wahai Muhammad): "Hai orangorang kafir! Aku tidak akan menyembah apa yang kamu sembah. Dan kamu tidak mahu menyembah (Allah) yang aku sembah. Dan aku tidak akan beribadat secara kamu beribadat. Dan kamu pula tidak mahu beribadat secara aku beribadat. Bagi kamu agama kamu, dan bagiku agamaku.

Surah ini diturunkan di Mekah dan ditujukan kepada kaum kafir musyrikin yang tidak mahu menerima seruan dan petunjuk kebenaran yang dibawakan Nabi s.a.w. kepada mereka. Menurut Ibn Jarīr, panggilan "Hai orang-orang kafir!" ini adalah disuruh oleh Allah S.W.T. agar disampaikan oleh Nabi Muhammad s.a.w. kepada orang-orang kafir tersebut, yang sejak awal berkeras menentang Rasul s.a.w. dan sudah diketahui dalam ilmu Allah S.W.T. bahawa sampai saat terakhir pun mereka tidak mahu menerima kebenaran. Mereka menentang Nabi s.a.w., dan dalam masa yang sama, Nabi s.a.w. juga tegas dalam sikapnya menentang penyembahan mereka kepada berhala, sehingga timbullah suatu bentuk pertandingan iaitu siapakah yang lebih kuat semangatnya mempertahankan pendirian masing-masing. Namun, apabila berhadapan dengan kekentalan semangat Nabi s.a.w., maka terasa oleh mereka peritnya dugaan tersebut, lalu ada yang mencela berhala mereka serta menyalahkan kepercayaan mereka. ${ }^{25}$

Dengan itu, pemimpin-pemimpin Quraisy telah bermuafakat untuk berdamai atau berkompromi dengan Nabi s.a.w. Orang yang diamanahkan oleh kaum Quraisy untuk berjumpa dengan Nabi s.a.w. bagi menangani perkara tersebut menurut riwayat Ibn Ishāq dari Sà̄d bin Minā, ialah al-Wālid bin al-Mughīrah, al-Ash bin Wā'il, al-Aswad bin al-Muțalib dan 'Umaiyyah bin Khalaf. Mereka telah mengemukakan satu usul damai sebagaimana berikut: "Ya Muhammad! Mari kita berdamai. Kami bersedia menyembah apa yang engkau sembah, tetapi engkau pun hendaknya bersedia pula menyembah apa yang kami sembah, dan di dalam segala urusan di negeri kita ini, engkau turut serta

25 Hamka, Tafsir al-Azhar, 10: 8132-8134. 
bersama kami. Kalau seruan yang engkau bawa ini memang ada baiknya daripada apa yang ada pada kami, biarlah kami turut merasakannya bersama. Dan jika pegangan kami ini yang lebih benar daripada apa yang engkau serukan itu maka engkau pun telah bersama merasakannya dengan kami, dan sama-sama mengambil bahagian di dalamnya",26

Tidak berapa lama setelah mereka mengemukakan usul ini, turunlah surah al-Kāfirūn yang mengarahkan Rasulullah s.a.w. agar menolak tawaran "sinkretisme". ${ }^{27}$ Surah al-Kāfirūn dimulai dengan ayat; "Katakanlah, hai orang-orang yang kafir! Aku tidaklah menyembah apa yang kamu sembah." Menurut tafsiran Ibn Kathīr, erti ayat 2, surah al-Kāfirūn: "Aku tidaklah menyembah apa yang kamu sembah," ialah menafikan perbuatan (nafi al-fi'lī). Ertinya bahawa perbuatan begitu tidaklah pernah aku (Nabi Muhammad s.a.w.) kerjakan. Manakala ayat 3, "Dan tidak pula kamu menyembah apa yang aku sembah," ertinya penyembahan oleh kaum kafir Quraisy dan Nabi Muhammad s.a.w. sama sekali tidak dapat didamaikan atau digabungkan. Ini adalah karena Nabi s.a.w. menyembah Allah S.W.T., manakala kaum kafir Quraisy menyembah kepada benda iaitu kayu atau batu yang diperbuat sendiri oleh mereka. Ayat 4 dan 5 pula, "Dan aku bukanlah penyembah sebagaimana kamu menyembah. Dan kamu bukanlah pula penyembah sebagaimana aku menyembah", secara jelas menunjukkan selain dari apa yang disembah itu berlainan, cara menyembah juga berlainan. Nabi Muhammad s.a.w. menyembah Allah S.W.T. dengan melakukan solat dengan syarat dan rukun yang telah ditentukan. Sedangkan kaum kafir Quraisy menyembah berhala itu dengan cara yang sangat berbeza. Oleh sebab itu, pegangan Nabi Muhammad s.a.w. dan kaum kafir Quraisy tidak dapat didamaikan sebagaimana yang termaktub dalam ayat 6 iaitu "Untuk kamulah agama kamu, dan untuk akulah agamaku." 28

${ }^{26}$ Ibid, Ibn Taimiyah, Taqi al-din, Al-Tafsīr Al-Kabīr (Beirut: Dar al-Kutub alIlmiah, t.t.), 7: 56-58.

27 Abu Jamin Roham, "sinkretisme" dalam Ensiklopedia Lintas Agama, 642-643.

${ }^{28}$ Ibn Kathīr, Abū al-Fidā' Ismā'̄̄l bin Kathīr. al-Tafsīr al-Qur'ān Al-Azīm (Kaherah: Maktabah Awlād al-Shaykh li al-Turāth, 1421H/2000M), 14: 486488. 
Surah ini memberi pedoman yang tegas bagi umat Nabi Muhammad s.a.w. bahawa akidah tidak dapat diperdamaikan. Tauhid dan syirik tidak dapat dipertemukan. Sekiranya yang haq hendak dipersatukan dengan yang batil, maka pada dasarnya yang batil yang akan menang. ${ }^{29}$ Hal ini kerana prinsip Tauhid merupakan pengiktirafan tentang keesaan Allah SWT serta penyembahan kepadaNya dalam segala hal tanpa adanya penyekutuan terhadapNya. ${ }^{30}$ Oleh sebab itu, akidah Tauhid itu tidak selari dengan sinkretisme, yang bererti menyatukan antara dua keimanan. Misalnya menyatukan di antara animisme dengan Tauhid, penyembahan berhala dengan sembahyang, menyembelih binatang untuk tujuan memuja hantu atau jin dengan membaca Bismillah dan sebagainya. ${ }^{31}$

Dalam konteks sinkretisme agama dan budaya pula, bagi Malik Bennabi sifat sebuah kehidupan bukanlah memecah-belah tetapi menggabungkan. Baginya, apabila unsur-unsur yang ada itu sesuai dan boleh diasimilasikan iaitu dalam situasi tidak bercanggah serta mencemar ketulenan agama, ia menjadi satu sintesis. Tetapi jika unsur-unsur itu pelbagai jenis dan tidak boleh dibandingkan kerana percanggahan yang boleh mencemarkan agama, ia menimbulkan sinkretisme, timbun-tambah dan kekalutan. Menurut beliau lagi, dunia Islam hari ini adalah hasil campuran saki baki yang diwarisi dari zaman selepas kekhalifahan Islam dan peninggalan kebudayaan baru daripada Barat. Hasil tersebut bukan akibat daripada orientasi pemikiran atau perhitungan saintifik, tetapi satu komposisi pelbagai warisan lama dan pembaharuan yang tidak ditapis. Unsur sinkretisme dari zaman yang berbeza dan dari kebudayaan yang berbeza tanpa sebarang penapisan telah membahayakan dunia Islam. ${ }^{32}$

Oleh itu bagi Bennabi, masyarakat perlu disedarkan terhadap kekeliruan mereka hingga terjadinya sinkretis dari unsur-unsur baru yang dipinjam dan saki-baki budaya yang diwarisi. Hal ini

29 Ibid.

30 Muh̦ammad Abū Zahrah, Al- 'Aqūdah al-Islāmiyyah Kamā Jāa bihā al-Qur'ān al-Karīm, (Kaherah: Majmu' al-Bu'ūth al-Islāmiyyah, t.t.), 20-21.

31 Hamka. Beberapa Tantangan Terhadap Ummat Islam di Masa Kini (Secularisme, Syncritisme dan Ma'siat) (Djakarta: Penerbit Bulan Bintang, 1970), 12-13.

32 Malek Bennabi, Islam and History of Society, terj. Asma Rashid (Islamabad: Islamic Research Institute, 1988), 101-102. 
kerana, kekalutan dari unsur-unsur yang tidak mungkin diasimilasikan ini telah menimbulkan perselisihan dan pertentangan yang hebat ibarat mempamerkan seorang lelaki yang soleh yang memakai serban sedang menikmati minuman yang memabukkan di kaunter sebuah bar. ${ }^{33}$ Dalam hal ini, Bennabi menyedari bahawa fenomena sinkretisme telah melanda masyarakat Islam serta menganggapnya sebagai berbahaya kepada umat Islam. Beliau melihat sinkretisme atau penggabungan turut berlaku dalam konteks agama Islam yang dianggapnya sebagai warisan masyarakat Islam dengan budaya Barat yang datang kemudiannya.

Namun Bennabi juga tidak menafikan bahawa ada kebudayaan yang lahir secara tidak dirancang. Ia lahir hasil pertembungan dua kebudayaan yang berbeza. Beliau berpendapat kebudayaan Islam dan kebudayaan Hindu yang mempunyai persamaan yang boleh dijadikan asas kebudayaan Asia-Afrika. Apa yang dimaksudkan adalah diwujudkan al-ta'ayush (coexistence) di antara keduanya. Walau bagaimanapun, ini tidaklah bererti mengambil elemen kebudayaan Islam dan Hindu sehingga melahirkan kebudayaan dan agama yang baru bergelar Din-i-Ilahi yang tidak dapat dinisbahkan kepada Islam mahupun Hindu seperti yang telah dilakukan oleh Akbar Khan di India dahulu. Pekerjaan yang begitu, menurut Malik adalah pekerjaan yang sia-sia. Beliau juga menegaskan tidak harus dilakukan sebarang 'tahrif' (perubahan) atau 'tabdil' (penukaran) kepada ajaran agama kerana perbuatan demikian akan menghancurkan ajaran itu seluruhnya, seperti apa yang telah berlaku kepada ajaran Kristian. $^{34}$ Dalam hal ini, Bennabi mencadangkan agar meneruskan kebudayaan yang diwarisi sebelum Islam dengan syarat tidak wujud pertentangan dengan ajaran Islam hingga berlakunya perubahan dalam doktrin ajaran Islam. Dalam erti kata yang lain, adat tradisi sebelum Islam boleh diteruskan di samping mengikis unsur sinkretisme dalam adat tradisi tersebut kerana sinkretisme lazimnya berlaku dalam proses interaksi antara dua tradisi yang berlainan.

${ }^{33}$ Ibid.

${ }^{34}$ Malik bin Nabi, Syurut al-Nahdah, terj. Umar Kamil Masqawi (Beirut: Dar alFikr, 1969), 143-145. 
Dalam hal ini H. O. K. Rahmat S. H. ada menjelaskan kemungkinan terdapatnya persamaan antara pelbagai kepercayaan contohnya antara kepercayaan primitif (animisme-dinamisme) dengan agama Islam. Antaranya ialah kepercayaan terhadap adanya roh dan hanya mengenai kehidupan dan sifat-sifat roh itulah kedua kelompok kepercayaan itu berbeza. Jika dalam kepercayaan animisme roh dianggap sebagai berkuasa mempengaruhi kehidupan manusia, maka dalam agama Islam misalnya, roh-roh tidak mempunyai kuasa, kerana hanya Allahlah yang berkuasa memberi manfaat dan mudarat kepada manusia. Demikian juga tentang perkara mimpi. Mengikut orang primitif, mimpi adalah pengalaman roh seseorang yang mengembara apabila tubuh kasarnya tertidur. Islam tidak mengatakan sedemikian, tetapi ada persamaan antara kepercayaan primitif dan kepercayaan Islam iaitu kadang-kadang mimpi itu mempunyai makna.

Manakala dalam hal pengorbanan pula, kepercayaan primitif telah lama mengenal amalan pengorbanan. Islam juga mensyariatkan amalan korban. Namun amalan pengorbanan keduanya berbeza misalnya dalam kepercayaan primitif, darah, daging dan jiwa binatang yang dikorbankan adalah sebagai persembahan roh yang dipuja, bertujuan memberi kemudahan kepada roh si mati dan lain-lain. Manakala, Islam mensyariatkan agar menyembelih korban pada hari raya Aidil-Adha dan pada hari-hari tasyriq sesudahnya. Namun hakikat pengorbanan dalam agama Islam itu tidaklah sama dengan hakikat pengorbanan dalam kepercayaan animism-dinamisme. Hal ini kerana dalam Islam, yang dihantar kepada Allah S.W.T. bukanlah darah atau daging haiwan korban itu, tetapi ketaqwaan orang yang melaksanakan ibadah korban yang rela mengorbankan sebahagian daripadanya hartanya semata-mata untuk mendapat keredhaan Allah S.W.T. ${ }^{35}$ Oleh itu bagi H.O.K. Rahmat, meneruskan amalan primitif yang ada persamaan dengan amalan dalam ajaran Islam tidaklah disebut sebagai sinkretisme selagi mana tidak mempamerkan percampuran yang bertentangan antara satu sama lain.

Pandangan H. O. K. Rahmat ini sejajar dengan Muhammad 'Uthman el-Muhammady dalam menjawab berhubung dengan

35 H.O.K. Rahmat, Dari Adam Sampai Muhammad: Sebuah Kajian Mengenai Agama-agama (Kota Bharu: Pustaka Aman Press Sdn. Bhd., 2008), 36-40. 
kemungkinan adanya persamaan antara amalan dalam ajaran Islam dan agama lain. Beliau menjelaskan ia perlu dilihat dalam rangka al-Qur'an sebagai penjaga atas erti-erti ajaran suci dalam sejarah manusia, tuntutan syara' dan ijma'. Sekiranya wujud persamaan antara Islam dan agama lain, ini adalah kerana agama-agama dunia asalnya terkena pengaruh ajaran para nabi terdahulu, justeru itu masih kelihatan peninggalan-peninggalan tentang persamaan tersebut. Namun kebenaran dengan kepenuhan, kedalaman serta kesempurnaannya hanya ada pada wahyu terakhir dalam sejarah umat manusia iaitu ajaran Islam yang diwahyukan kepada Nabi Muhammad s.a.w. ${ }^{36}$

\section{Adat Tradisi Dari Perspektif Al-Qur'an dan Sarjana Islam}

Adat tradisi lazimnya dikaitkan dengan ajaran dan kepercayaan terdahulu yang sebahagiannya mungkin telah terpesong oleh kejahilan manusia atau sesebuah masyarakat. Manakala kehadiran seseorang Nabi bertujuan memperbetulkan apa yang terpesong. Dengan itu, adat tradisi secara keseluruhan bukanlah sesuatu yang harus ditentang. Dalam hal ini, Al-Quran ada ada menyebutkan bahawa memuji dan memuja orang tua merupakan amalan masyarakat jahiliah sebelum mereka memeluk Islam. Setelah itu, Islam mengajar mereka agar menggantikannya dengan amalan memuji dan memuja Allah S.W.T. Hal ini disebutkan dalam firman Allah S.W.T. sebagaimana berikut:

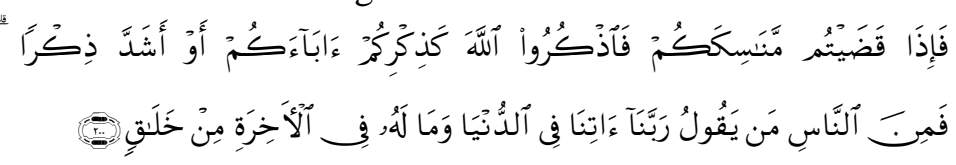

Al-Baqarah 2:200

Bermaksud: Kemudian apabila kamu telah selesai mengerjakan amalan ibadat haji kamu, maka hendaklah kamu menyebut-nyebut dan mengingati Allah (dengan membesarkanNya) sebagaimana kamu dahulu menyebutnyebut (memuji-muji) datuk nenek kamu, bahkan dengan sebutan yang lebih lagi. Dalam pada itu, ada di antara

36 Muhammad 'Uthman el-Muhammady, "Pluralisme Agama: Beberapa Persolaan Dilihat Dari Pandangan Arus Perdana Islam," dalam Pluralisme Agama: Satu Gerakan Iblis Memurtadkan Ummah (Kuala Lumpur: MUAFAKAT, 2012), 153-154. 
manusia yang (berdoa dengan) berkata: "Wahai Tuhan kami! berilah kami kebaikan) di dunia". (orang-orang ini diberikan kebaikan di dunia) dan tidak ada baginya sedikitpun kebaikan di akhirat.

Al-Țabarī dan Ibn Kathīr dalam tafsir mereka, menjelaskan bahawa amalan masyarakat Jahiliah sewaktu wuquf pada musim haji adalah menyebut-menyebut perihal ayah dan ibu mereka seperti kanak-kanak yang mendambakan kedua ibu bapanya. ${ }^{37}$ Antara mereka ada yang menyebut bahawa ayah mereka sedang makan, membawa barangan, menggunting anak rambut seseorang, menyembelih sembelihan dan pelbagai lagi. Perbuatan mereka ini seolah-olah tiada sesuatu pun yang diingati melainkan perbuatanperbuatan bapa mereka. Lalu turunlah ayat ini sebagai perintah agar mereka mengingati Allah malah dengan lebih lagi berbanding mengingati orang tua mereka. ${ }^{38}$

Berdasarkan ayat ini dapatlah dijelaskan bahawa amalan yang menjadi kebiasaan manusia sebelum memeluk Islam iaitu memujimuja orang tua mereka setelah selesai ibadat haji, disarankan oleh Allah S.W.T. supaya diubah kepada memuji-muja Allah S.W.T. Hal ini menunjukkan amalan-amalan kebiasaan (adat) manusia itu tidak perlu ditinggalkan sepenuhnya, sebaliknya ia perlu disesuaikan dengan kehendak ajaran Islam. Hal ini selaras dengan pandangan H.O.K Rahmat dan 'Uthman el-Muhammady yang menjelaskan kemungkinan adanya persamaan dalam amalan iaitu amalan memuji-muja juga disarankan oleh Islam dengan cara yang berbeza iaitu memuji-muja Allah SWT bukannya orang tua kita.

Al-Shahrastānī pula menjelaskan tradisi dan sebahagian adat resam orang Arab Jahiliah telah diperakui oleh Islam. Antara tradisi tersebut adalah tidak mengahwini ibu-ibu mereka, anakanak perempuan, ibu saudara sebelah ibu dan ibu saudara sebelah bapa. Seterusnya, mereka menceraikan talak tiga secara berasingan. Mereka juga mengerjakan haji di Baitullah, melakukan umrah, berihram, melakukan tawaf sebanyak tujuh kali, menyapu Hajar Aswad, bersa'ie antara Safa dan Marwah, bertalbiah (tetapi sebahagian mereka mengucapkan talbiah dengan

37 Ibn Kathīr, al-Tafsīr al-Qur'ān Al-Azìm, 261-265.

38 Al-Țabarī, Abū Ja far Muh̦ammad bin Jarīr, Tafsīr al-Țabarī Jāmi al-Bayān 'an Ta'wīl aAy al-Qur'ān (Hijr: Markaz al-Buhūth wa al-Dirāsāt al'Arabiyyah wa al-Islāmiyyah, t.t.), 3: 535-536. 
ucapan syirik), berwuquf, menyembelih korban, melontar Jamrah dan mengharamkan bulan-bulan Haram. Mereka tidak suka melakukan kezaliman di Tanah Haram. Bagi amalan talbiah yang dicemari unsur syirik pula diterima oleh Islam dengan diubah kepada menyeru Allah SWT tanpa ada penyekutuan atau syirik. ${ }^{39}$

Perkara yang sama turut ditegaskan oleh Md. Salleh Haji Ahmad. Menurut beliau, ketika kedatangan Islam, masyarakat Arab mempunyai berbagai-bagai adat resam, kemudian ia memperakukan mana-mana adat yang sesuai dan selari dengan matlamat dan prinsip Islam, seterusnya ditolak mana-mana adat yang bercanggah dengan syariatnya. Kemudian dipinda atau diperbaiki beberapa 'urf dan adat supaya selaras dengan haluan dan matlamatnya. 'Urf juga wajib diambil kira dalam proses hukum, kerana sesuatu adat yang dikenali dan dihayati oleh masyarakat telah menjadi sebahagian dari keperluan mereka di samping ia selari dengan kepentingan-kepentingan mereka. ${ }^{40}$

Bennabi pula menyedari pentingnya mekanisme mempertahankan diri yang diilhamkan oleh sesebuah masyarakat untuk melindungi rangkaian hubungan sosial daripada kemudaratan atau bahaya. Dengan itu, semua ajaran dan nilai suci yang meliputi kehidupan sesebuah masyarakat, walaupun masyarakat primitif adalah manifestasi yang berlainan bagi mekanisme pertahanan yang sama. Oleh sebab itu, semua undangundang sama ada yang datang melalui wahyu Tuhan ataupun yang dibuat oleh manusia, pada hakikatnya merupakan langkah pertahanan untuk menjaga rangkaian hubungan sosial. Tanpanya, hidup manusia tidak akan berjaya dan tidak mampu mencapai kemajuan dari segi moral atau kebendaan. ${ }^{41}$

Dengan itu, Bennabi menegaskan peranan agama dalam proses perubahan masyarakat melalui perubahan dalam individu. Peranan agama yang dimaksudkan oleh Bennabi adalah agama

39 Al-Shahrastān̄̄, Abū al-Fattāh Muhammad 'Abd al-Karīm Ibn Ab̄̄ Bakr Ahmad. al-Milāl wa al-Nihāl (Beirut: Dār al-Fikr, t.t.), 276-278.

${ }^{40}$ Md. Saleh bin Hj. Md. @ Haji Ahmad. “Urf dan Adat Semasa di Malaysia sebagai asas Penentuan Hukum yang Tidak Dinaskan," dalam Fiqh Malaysia Ke Arah Membina Fiqh Tempatan Yang Terkini (Kuala Lumpur: Universiti Malaya, 2000), 111.

${ }^{41}$ Malik Bennabi, Asal Usul Masyarakat Manusia: Rangkaian Hubungan Sosial, terj. Muhammad 'Uthman el-Muhammady (Kuala Lumpur: Dewan Bahasa dan Pustaka, 1991), 117. 
Islam, perubahan sosial yang berlaku pula termasuklah meninggalkan sebahagian kepercayaan tradisi dan adat kebiasaan yang bertentangan dengan ajaran Islam. Hal ini kerana menurut beliau, untuk membangunkan semula kebudayaan di negaranegara Islam, hendaklah dibersihkan adat-adat, warisan-warisan, sistem-sistem akhlak dan sistem sosial daripada perkara yang bercanggah dengan ajaran Islam. ${ }^{42}$ Manakala proses perubahan melalui individu pula, menurutnya akan berkesan dengan bantuan faktor-faktor lain seperti penekanan terhadap aspek pendidikan. Aspek pendidikan yang dimaksudkan adalah pendidikan akhlak agama, estetik, logika kerja dan teknologi. ${ }^{43}$

Di samping itu menurut Bennabi, kebiasaan-kebiasaan dan tradisi-tradisi termasuk dalam lingkungan kebudayaan sesebuah masyarakat yang membentuk cara kehidupan dan tingkah laku individu di dalamnya dengan ciri-ciri khas. ${ }^{44}$ Berdasarkan pada kefahamannya mengenai nilai yang ada dalam budaya yang berbeza antara sebuah masyarakat dengan sebuah masyarakat yang lain, Bennabi mengusulkan keperluan pengasasan ilmu sosiologi Islam atau ilmu sosiologi khas masyarakat Islam. Ini kerana ilmu sosiologi moden sedia ada, lahir dan berkembang dalam masyarakat Barat yang sangat berbeza dengan masyarakat Islam. Dengan itu, definisi atau konsep sinkretisme serta bagaimana harus menanggapinya dalam masyarakat Islam menurut perspektif Islam perlu difikirkan sebagai respon kepada penggunaan terminologi ini dalam masyarakat Islam menggunakan kerangka Barat.

Dalam konteks Malaysia pula, Mahmood Zuhdi Hj. Ab. Majid mejelaskan bahawa kedatangan Islam ke Nusantara telah banyak mengubah struktur kebudayaan tempatan, namun tidak semua nilai-nilai yang lama itu diganti sepenuhnya. Sebagai sebuah agama yang fleksible dan universal, Islam tidak mempunyai dasar untuk menghapuskan atau menekan kebudayaan

42 Ibid., 57.

43 Usman Syihab, "Agama Dan Perubahan Masyarakat Menurut Malik Bennabi," 129-171.

44 Usman Syihab, "Agama Dan Perubahan Masyarakat Menurut Malik Bennabi," AFKAR 10 (2009), 129-171. 
tempatan di mana ia bertapak ${ }^{45}$ yang berkemungkinan masih bertentangan dengan prinsip Tauhid. Dalam masa yang sama, Islam amat mementingkan kesucian dan ketulenan ajarannya daripada dicemari oleh elemen sinkretis warisan daripada kebudayaan sebelum Islam. Dengan itu, adalah penting untuk memberi tafsiran yang jelas tentang sinkretisme dalam masyarakat serta cara menanggapinya agar kesucian dan ketulenan Islam terpelihara.

Berdasarkan pandangan sarjana Islam terhadap adat tradisi tersebut dapatlah disimpulkan bahawa adat tradisi mempunyai kekuatan untuk membimbing masyarakat dan boleh diteruskan selagi mana ia tidak bercanggah dengan ajaran Islam. Dalam hal ini, pengakaji kurang bersetuju dengan sebahagian tindakan golongan reformis yang ingin menghapuskan adat tradisi untuk mengelakkan bid'ah.

\section{Cara Menanggapi Sinkretisme Dalam Adat Tradisi}

Setelah meneliti konsep sinkretisme daripada perspektif Barat dan Islam, seterusnya penelitian terhadap adat dan budaya tradisi dari perspektif Islam dibuat, pengkaji ingin mencadangkan konsep dan cara menanggapi sinkretisme khusus dalam adat dan tradisi dalam kalangan masyarakat Islam yang pengkaji sandarkan pada surah al-Baqarah, ayat 200 sebagaimana yang telah dibincangkan dalam rajah 1 di bawah:

Rajah 1: Cara Menanggapi Sinkretisme Dalam Adat Tradisi

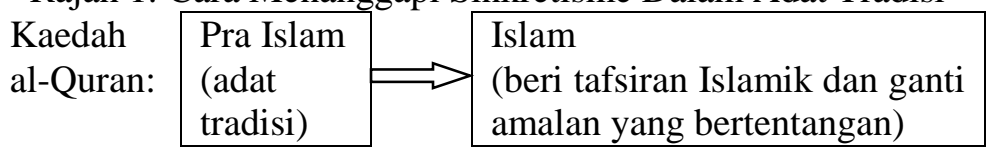

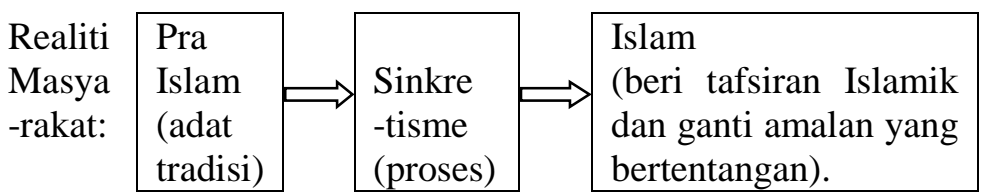

Dalam surah al-Baqarah, ayat 200 tersebut membenarkan adat tradisi memuji-muja dikekalkan tetapi puji-pujian tersebut haruslah diberikan kepada Allah S.W.T. Dalam hal ini, tradisi

45 Mahmood Zuhdi Hj. Ab. Majid, "Fiqh Malaysia: Konsep dan Cabaran," dalam Fiqh Malaysia Ke Arah Membina Fiqh Tempatan Yang Terkini (Kuala Lumpur: Universiti Malaya, 2000), 15. 
memuji-muja tersebut diberi tafsiran yang Islamik dengan menukar bentuk dan tujuan memuji-muja tersebut daripada nenek moyang kepada Allah S.W.T. Walau bagaimanapun, jika diaplikasikan ke dalam masyarakat, dalam proses menukarkan bentuk dan tujuan adat tradisi tersebut, ada kemungkinan berlakunya sinkretisme. Jika diambil amalan adat yang sama dalam ayat tersebut sebagai contoh, ada kemungkinan proses sinkretisme berlaku jika masyarakat jahiliah tersebut memuji-muja Allah S.W.T. dan pada masa yang sama turut memuji-muja nenek moyang mereka. Dalam perkara-perkara lain tentang adat tradisi masyarakat yang diwarisi khususnya di kawasan Nusantara, proses sinkretisme sedemikian banyak berlaku.

Oleh itu, makalah ini mencadangkan bahawa sinkretisme ditanggapi sebagai proses sementara dalam rangka pengislaman masyarakat. Hal ini turut mengambil kira sinkretisme juga boleh berlaku dalam bentuk proses sama ada akan menghasilkan agama sinkretik ataupun tidak sebagaimana pandangan Colpe. Dalam masa yang sama, pengkaji sependapat dengan pandangan sarjana Islam yang lain yang tidak membenarkan sinkretisme tetapi membenarkan penerusan adat tradisi. Pengkaji turut menegaskan bahawa Islam bukanlah agama sinkretik kerana proses sinkretisme yang berlaku dalam kalangan masyarakat Islam adalah reaksi awal pertembungan antara kepercayaan sebelum Islam dengan agama Islam.

\section{Penutup}

Dengan ini, kajian ini membuka ruang kepada adat tradisi masyarakat untuk diteruskan berdasarkan kaedah di atas walaupun ia menyebabkan berlakunya sinkretisme secara tabii. Hal ini kerana sinkretisme ini hanyalah proses tabii yang tidak dapat dielakkan pada peringkat awal pengislaman dan bukanlah tujuan sebenar pengislaman. Tujuan sebenar hanyalah memenuhi kehendak Islam yang bersifat Tauhidik. Hal ini juga selari dengan kajian-kajian lepas tentang adat dalam masyarakat Melayu. Antaranya Mohamad bin Muda yang mengkaji adat kebiasaan di Kelantan dan mengemukakan adat yang baik sebagai satu sumber hukum seperti menziarahi jenazah serta memberi sumbangan 
berbentuk wang ringgit, gula dan beras. ${ }^{46}$ Begitu juga Siddiq Fadzil yang menjelaskan bahawa apabila berlakunya pertembungan Islam dengan budaya peribumi seperti adat pepatih dalam isu Pusaka Tinggi, Islam tidak terus membanterasnya, tetapi tidak pula terus menerimanya. Sebaliknya, adat peribumi diubahsuai agar tidak menyalahi ajaran Islam dan diberi kesempatan untuk terus hidup selama ia diperlukan oleh pengamalnya. ${ }^{47}$ Tidak kurang juga pengkaji yang menyarankan agar usaha sentiasa dilakukan agar adat tradisi tersebut selari dengan ajaran Islam ${ }^{48}$ atau dalam erti kata lain proses sinkretisme telah dihakis sepenuhnya. Hal ini kerana Tauhid bertentangan dengan khurafat dan mitos. ${ }^{49}$

\section{Bibliografi}

Abu Jamin Roham. Ensiklopedia Lintas Agama. Jakarta: Emerald, 2009.

Al-Shahrastān̄̄, Abū al-Fattāh Muhammad 'Abd al-Karīm Ibn Ab̄̄ Bakr Ahmad. al-Milāl wa al-Nihāl. Beirut: Dār al-Fikr, t.t.

Al-Țabarī, Abū Ja far Muḥammad bin Jarīr. Tafsīr al-Tabarī Jāmi" al-Bayān 'an Ta'wīl aAy al-Qur'ān. Jilid ke-3. Hijr: Markaz alBuhūth wa al-Dirāsāt al- ${ }^{-}$Arabiyyah wa al-Islāmiyyah, t.t.

Anita Maria Leopold \& Jeppe Sinding Jensen, ed. Syncretism in Religion. New York: Routledge, 2004.

Carsten Colpe. "syncretism," dalam The Encyclopedia of Religion, ed. Mircea Eliade. New York: McMillan Publishing, Jilid ke-14, 1987. Charles Stewart. "Syncretism as a Dimension of Nationalist Discourse in Modern Greece," dalam Syncretism/ AntiSyncretism: The Politics of Religious Synthesis, ed. Charles Stewart \& Rosalind Shaw, 127-144. London \& New York: Routledge, 1994.

46 Mohamad bin Muda, “'Urf Tempatan Di Negeri Kelantan Dan Kesannya Terhadap Perubahan Hukum: Satu Analisis," disertasi, Universiti Malaya, Kuala Lumpur, 2004, x.

47 Siddiq Fadzil, "Pertembungan Islam Dengan Budaya Peribumi: Pengalaman Alam Melayu," dalam Hukum Islam dan Budaya Tempatan, ed. Md. Salleh Hj. Ahmad et.al (Kuala Lumpur: Universiti Malaya, 2004), 137-156.

48 Siti Fauziah Mohd Amin, "Adat-adat Masyarakat Melayu Brunei Daerah Membakut Sabah: Kajian Menurut Perspkektif Islam, disertasi, Universiti Malaya, Kuala Lumpur, 2008, x.

49 Ismail R. al-Faruqi dan Lois Lamya al-Faruqi, The Cultural Atlas of Islam, 87. 
Edwin Zehner. "Orthodox Hybridities: Anti-Syncretism and Localization in the Evangelical Christianity of Thailand," Anthropological Quarterly 78, no. 3: 585-617, 2005.

H.O.K. Rahmat. Dari Adam Sampai Muhammad: Sebuah Kajian Mengenai Agama-agama. Kota Bharu: Pustaka Aman Press Sdn. Bhd., 2008.

Hamka. Beberapa Tantangan Terhadap Ummat Islam di Masa Kini (Secularisme, Syncritisme dan Ma'siat). Djakarta: Penerbit Bulan Bintang, 1970.

Hamka. Tafsir al-Azhar. Singapura: Pustaka Nasional Pte Ltd, 2003. Hendrik Kreamer, "Syncretism," dalam Syncretism in Religion, ed. Anita Maria Leopold \& Jeppe Sinding Jensen, 39-47. New York: Routledge, 2004.

Ibn Kathīr, Abū al-Fidā' Ismā'īl bin Kathīr. al-Tafsīr al-Qur'ān Al-Azìm. Kaherah: Maktabah Awlād al-Shaykh li al-Turāth, 1421H/2000M.

Ibn Taimiyah, Taqi al-din. Al-Tafsìr Al-Kabīr. Beirut: Dar alKutub al-Ilmiah, t.t.

Ismail R. al-Faruqi dan Lois Lamya al-Faruqi. The Cultural Atlas of Islam. U.S.A.: International Institute of Islamic Thought, 1926.

Mahmood Zuhdi Ab. Majid. "Fiqh Malaysia: Konsep dan Cabaran," dalam Fiqh Malaysia Ke Arah Membina Fiqh Tempatan Yang Terkini. Kuala Lumpur: Universiti Malaya, 2000.

Malek Bennabi. Islam and History of Society, terj. Asma Rashid. Islamabad: Islamic Research Institute, 1988.

Malik Bennabi. Asal Usul Masyarakat Manusia: Rangkaian Hubungan Sosial, terj. Muhammad 'Uthman el-Muhammady. Kuala Lumpur: Dewan Bahasa dan Pustaka, 1991.

Malik bin Nabi. Syurut al-Nahdah, terj. Umar Kamil Masqawi. Beirut: Dar al-Fikr, 1969.

Md. Saleh bin Hj. Md. @ Haji Ahmad. “Urf dan Adat Semasa di Malaysia sebagai asas Penentuan Hukum yang Tidak Dinaskan," dalam Fiqh Malaysia Ke Arah Membina Fiqh Tempatan Yang Terkini, 99-125. Kuala Lumpur: Universiti Malaya, 2000.

Michael Pye. "Syncretisme and Ambiguity," Numen: International Review for the History of Religions 18, no. 2: 83-93, 1971. 
Mohamad bin Muda. "Urf Tempatan Di Negeri Kelantan Dan Kesannya Terhadap Perubahan Hukum: Satu Analisis." Disertasi, Universiti Malaya, Kuala Lumpur, 2004.

Muhammad 'Uthman el-Muhammady. "Pluralisme Agama: Beberapa Persolaan Dilihat Dari Pandangan Arus Perdana Islam," dalam Pluralisme Agama: Satu Gerakan Iblis Memurtadkan Ummah, 139-157. Kuala Lumpur: MUAFAKAT, 2012.

Muḥammad Abū Zahrah. Al-'Aqīdah al-Islāmiyyah Kamā Jāa bihā al-Qur'ān al-Karìm. Kaherah: Majmu' al-Bu'ūth alIslāmiyyah, t.t.

Peter Schineller. "Inculturation and syncretism: what is the real issue?," International Bulletin of Missionary Research 16, no. 2: 50-53, 1992.

Robert Baird. "Syncretism and the History of Religion" dalam Syncretism in Religion, ed. Anita Maria Leopold \& Jeppe Sinding Jensen, 48-58. New York: Routledge, 2004.

Robert J. Schreiter. "Defining Syncretism: An Interim Report", International Bulletin of Missionary Research 17, no. 2: 50-53, 1993.

Rosalind Shaw \& Charles Stewart. "Introduction: Problematizing Syncretism," dalam Syncretism/ Anti-Syncretism: The Politics of Religious Synthesis, ed. Charles Stewart \& Rosalind Shaw, 126. London \& New York: Routledge, 1994.

Siddiq Fadzil. "Pertembungan Islam Dengan Budaya Peribumi: Pengalaman Alam Melayu," dalam Hukum Islam dan Budaya Tempatan, ed. Md. Salleh Hj. Ahmad et.al, 137-156. Kuala Lumpur: Universiti Malaya, 2004.

Siti Fauziah Mohd Amin. "Adat-adat Masyarakat Melayu Brunei Daerah Membakut Sabah: Kajian Menurut Perspkektif Islam.” Disertasi, Universiti Malaya, Kuala Lumpur, 2008.

Siv Ellen Kraft. "To mix or not to mix: Syncretism/ antisyncretism in the history of theosophy," Numen: International Review for the History of Religions 49, no. 2, 2002.

Usman Syihab. "Agama Dan Perubahan Masyarakat Menurut Malik Bennabi," AFKAR 10: 129-171, 2009.

William L. Reese. Dictionary of Philosophy and Religion. New Jersey: Humanities Press Inc., 1980. 